\title{
On Packing of Unequal Squares in a Rectangle
}

\author{
Antal Joós \\ University of Dunaújváros, Institute of Computer Engineering, Department of \\ Mathematics, Táncsics M. u. 1/a, 2400 Dunaújváros, Hungary, joosa@uniduna.hu
}

\begin{abstract}
It is known that the sum of the squares of the reciprocals, of positive integer numbers, is finite. It can be asked... What is the smallest area rectangle into which all the squares of sides of length the reciprocals of the positive integers can be packed? In connection with the investigations related to mathability and to applications of computer assisted methods, for considering mathematical problems, an improvement for the best known $\epsilon$ is presented, herein. The GNU program, Octave, was used for the calculations.
\end{abstract}

Keywords: Mathability; Cognitive Infocommunications; Computer Assisted Methods; Packing; Square

\section{Introduction}

Mathability refers to a branch of cognitive infocommunications that investigates any combination of artificial and natural cognitive capabilities, relevant to mathematics, including a wide spectrum of areas ranging from low-level arithmetic operations, to high-level symbolic reasoning. The concept of Cognitive Infocommunications (CogInfoCom) was introduced in the paper [1]. Some of its further general properties were described in the papers [2] and [3] and in the book [4]. The educational aspects of CogInfoCom and mathability were investigated, among others, in [5-12] while other CogInfoCom related applications of cognitive capabilities are presented in [13-20].

Questions related to mathability and to computer based methods for investigations of mathematical problems have been studied by several authors in recent years [2125]. T work has contributed to these investigations. A computer assisted method for a packing of squares, of sides of length $\frac{1}{2}, \frac{1}{3}, \frac{1}{4}, \ldots$ is presented.

The paper [26], motivated me to present a computer assisted method for a problem of Meir and Moser [27]. The calculation is performed in Octave, available at https://www.gnu.org/software/octave/download. 


\section{The Problem}

It is said the squares $S_{1}, S_{2}, S_{3}, \ldots$ can be packed into a rectangle if it is possible to apply translations and rotations to the sets $S_{n}$ so that the resulting translated and rotated squares are contained in the rectangle and have mutually disjoint interiors.

Meir and Moser [27], in 1968, originally noted that since:

$\sum_{i=2}^{\infty} \frac{1}{i^{2}}=\frac{\pi^{2}}{6}-1$

it is reasonable to ask whether the set of squares of sides of length $\frac{1}{2}, \frac{1}{3}, \frac{1}{4}, \ldots$, which is called the reciprocal squares, can be packed into a rectangle of area $\frac{\pi^{2}}{6}-1$. Failing that, find the smallest $\epsilon$ such that the reciprocal squares can be packed into a rectangle $R$ of area $\frac{\pi^{2}}{6}-1+\epsilon$. This question can be found in e.g. [28].

Meir and Moser [27] in 1968 showed that the smallest square containing the reciprocal squares is the square of side $\frac{5}{6}$ which shows that $\epsilon<\frac{1}{205}$. Jennings [29] in 1994 gave a rectangle of dimensions $\frac{47}{60} \times \frac{5}{6}$ containing the reciprocal squares which shows that $\epsilon<\frac{1}{127}$

Ball [30] in 1996 gave a rectangle of dimensions $\frac{629}{1000} \times \frac{31}{30}$ containing the reciprocal squares which shows that $\epsilon<\frac{1}{198}$

Paulhus [26] in 1997 gave a rectangle of dimensions:

$0.5 \times\left(2\left(\frac{\pi^{2}}{6}-1\right)+1.606553066 \cdot 10^{-9}\right)$

containing the reciprocal squares which shows that:

$\epsilon<\frac{1}{1244918662}=8.032653301 \ldots \cdot 10^{-10}$

The author [31] in 2018 has found a mistake in the proof of Paulhus. Grzegorek and Januszewski [32] in 2019 filled this gap in the proof of Paulhus. In this paper a new estimate for $\epsilon$ is presented.

\section{Construction}

\section{Theorem 1}

The rectangle of dimensions $0.5 \times\left(2\left(\frac{\pi^{2}}{6}-1\right)+1.3638133072 \cdot 10^{-9}\right)$ contains the reciprocal squares which shows that $\epsilon<6.819066536 \cdot 10^{-10}$

From the following construction it comes the proof of the theorem. 
The square of size $\frac{1}{i}$ is referred by (the square) $i$. In this paper the width of a rectangle will always refer to the shorter side and the length will always refer to the longer side of the rectangle. Let $R$ be the rectangle of dimensions $\frac{1}{2} \times 2\left(\frac{\pi^{2}}{6}-1\right)$ in which the squares are packed first. It is assumed, that the width of $R$ is horizontal. Let $\mathrm{l}_{0}=0.00001903$. Let $R^{\prime}$ be the square of side length $l_{0}$.

Let $A=1622971324, \quad B=1648721271, \quad C=2675827341, \quad D=$ $2718281828, E=2761408695$. The numbers $A, B, C, D$ and $E$ comes from [26]. Let $n_{0}=E+1, n_{i}=\left\lfloor n_{i-1}\left(1+l_{0}\right)\right\rfloor$ for $i \geq 1$ where $[$.$\rfloor is the floor function$ and $n_{18}^{\prime}=2762386911$. Observe the squares from $n_{i-1}$ to $n_{i}-1$ fit in a row of $R^{\prime}$. Let $A_{1}=1016225800, A_{2}=1000000440, C^{\prime}=2633103139$ and $C_{0}=2674879766, \ldots, C_{18}=2675796170$ so that

$\sum_{i=C_{j}}^{C_{j+1}-1} \frac{1}{i}<l_{0} \leq \sum_{i=C_{j}}^{C_{j+1}} \frac{1}{i}$ for $\mathrm{j}=0, \ldots, 18$

The numbers $C_{1}, \ldots, C_{18}$ are calculated with the help of Octave and Lemma 1.

Lemma 1. The following is true:

$$
\ln \frac{n+m+1}{n}<\frac{1}{n}+\cdots+\frac{1}{n+m}<\ln \frac{n+m}{n-1}
$$

where $n$ and $m$ are positive integers and $n \neq 1$

Proof of Lemma 1. After using the lower and upper sums of the function $x \mapsto \frac{1}{x}$ the estimates are trivial.

By Lemma 1, it is true:

$$
\frac{1}{n}+\cdots+\frac{1}{n+m} \approx \frac{\ln \frac{n+m+1}{n}+\ln \frac{n+m}{n-1}}{2}
$$

The numerical estimations based on the Lemma 1. The following two short Octave retval functions help the calculations:

$$
\begin{aligned}
& \text { function retval }=\operatorname{dist} U(\mathrm{k}, \mathrm{v}) \\
& \text { retval }=\log (\mathrm{v} /(\mathrm{k}-1)) ; \\
& \text { endfunction } \\
& \text { function retval }=\operatorname{distL}(\mathrm{k}, \mathrm{v}) \\
& \text { retval }=\log ((\mathrm{v}+1) / \mathrm{k}) ;
\end{aligned}
$$

endfunction. 
By Lemma 1, the function distL(k,v) returns an lower bound of the sum $\frac{1}{k}+\cdots+\frac{1}{v}$ and the function $\operatorname{dist} \mathrm{U}(\mathrm{k}, \mathrm{v})$ returns an upper bound of the $\operatorname{sum} \frac{1}{k}+\cdots+\frac{1}{v}$.

The following is used:

Lemma 2. The squares $C_{0}, C_{0}+1, \ldots, C, n_{18}^{\prime}, n_{18}^{\prime}+1, \ldots, n_{100001}-1$,

$n_{100251}, n_{100251}+1, \ldots$ can be packed in $R^{\prime}$.

Proof of Lemma 2. The squares from $C_{0}$ to $C$ are packed in rows of length no greater than $l_{0}$ in the square $R^{\prime}$.

If $1 \leq i \leq 18$, then in the $i$ th row the squares go from $C_{i-1}$ to $C_{i}-1$ (Figure 1). Observe, the squares from $C_{i-1}$ to $C_{i-1}$ fit in the $i^{\text {th }}$ row.

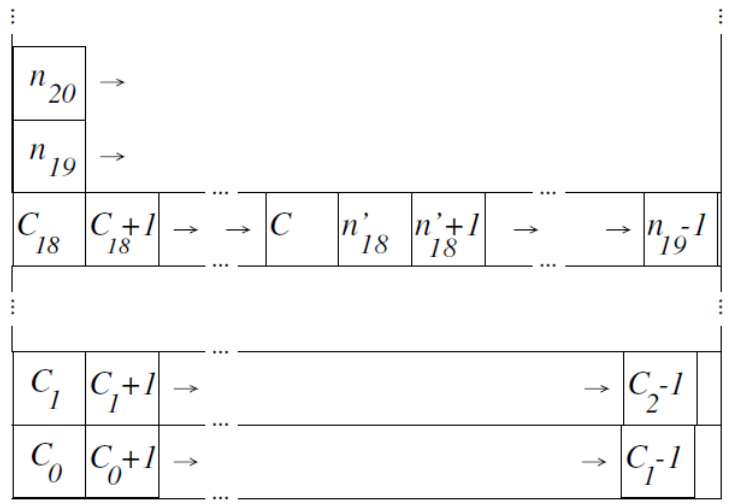

Figure 1

The $i$ th row in $R^{\prime}(1 \leq i \leq 19)$

By Lemma 1 and Octave, in the 19th row the squares go from $C_{18}$ to $C$ and from $n_{18}^{\prime}$ to $n_{19}-1$. If $20 \leq i \leq 100001$, then in the $i$ th row the squares go from $n_{i-1}$ to $n_{i}-1$. Observe, the squares from $n_{i-1}$ to $n_{i}-1$ fit in the $i^{\text {th }}$ row. If $100002 \leq$ $i$, then in the $i^{\text {th }}$ row the squares go from $n_{i+249}$ to $n_{i+250}-1$ (Figure 2). Observe, the squares from $n_{i+249}$ to $n_{i+250}-1$ fit in the $i^{\text {th }}$ row. 


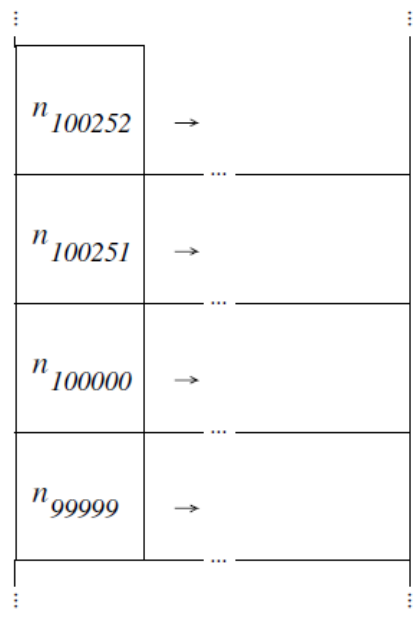

Figure 2

The $i$ th row in $R^{\prime}(100000 \leq i \leq 100003)$

Now:

$$
\begin{aligned}
& n_{i}=\left\lfloor n_{i-1}\left(1+l_{0}\right)\right\rfloor>n_{i-1}\left(1+l_{0}-\frac{1}{n_{i-1}}\right) \\
& >n_{i-2}\left(1+l_{0}-\frac{1}{n_{i-1}}\right)\left(1+l_{0}-\frac{1}{n_{i-2}}\right) \\
& >n_{i-2}\left(1+l_{0}-\frac{1}{n_{i-2}}\right)^{2}>\cdots>n_{18}\left(1+l_{0}-\frac{1}{n_{18}}\right)^{i-18}
\end{aligned}
$$

for $i>18$, Thus:

$\sum_{i=1}^{19} \frac{1}{C_{i-1}}+\sum_{i=20}^{100} \frac{1}{n_{i-1}}+\sum_{i=100002}^{\infty} \frac{1}{n_{i+249}}$

$<0.00000000710190 \ldots+\sum_{i=20}^{100001} \frac{1}{n_{18}\left(1+l_{0}-\frac{1}{n_{18}}\right)^{i-19}}$

$\ldots+\sum_{i=100002}^{\infty} \frac{1}{n_{18}\left(1+\mathrm{l}_{0}-\frac{1}{\mathrm{n}_{18}}\right)^{i+231}}$

$=0.00000000710190 \ldots+\frac{1}{n_{18}\left(1+l_{0}-\frac{1}{n_{18}}\right)} \sum_{i=0}^{99} \frac{1}{\left(1+l_{0}-\frac{1}{n_{18}}\right)^{i}}$ 


$$
\begin{aligned}
& +\frac{1}{n_{18}\left(1+\mathrm{l}_{0}-\frac{1}{\mathrm{n}_{18}}\right)^{100233} \sum_{i=0}^{\infty} \frac{1}{\left(1+\mathrm{l}_{0}-\frac{1}{\mathrm{n}_{18}}\right)^{i}}} \\
& =0.00000000710190 \ldots+\frac{1}{n_{18}\left(1+\mathrm{l}_{0}-\frac{1}{\mathrm{n}_{18}}\right)} \frac{1-\frac{1}{\left(1+\mathrm{l}_{0}-\frac{1}{\mathrm{n}_{18}}\right)^{99982}}}{1-\frac{1}{1+\mathrm{l}_{0}-\frac{1}{\mathrm{n}_{18}}}} \\
& +\frac{1}{n_{18}\left(1+\mathrm{l}_{0}-\frac{1}{\mathrm{n}_{18}}\right)^{100233}} \frac{1}{1-\frac{1}{1+\mathrm{l}_{0}-\frac{1}{\mathrm{n}_{18}}}}<0.000019017<l_{0}
\end{aligned}
$$

Octave was used to the numerical calculations. Thus the squares fit in $R^{\prime}$, which is the statement of the lemma.

Proof of Theorem 1. It is assumed that the squares up to $10^{9}$ are packed in $R$ as in [26]. By [26], there is a rectangle $R_{L}$ of length and width at most $l_{0}$, which has no common interior point with the squares up to $10^{9}$. By Lemma 2, it is necessary to find a place to pack the squares from $10^{9}+1$ to $C_{0}-1$, from $C+1$ to $n_{18}^{\prime}-1$ and from $n_{100001}$ to $n_{100251}-1$.

Let the squares from $10^{9}+1$ to $C_{0}-1$ and from $C+1$ to $n_{18}^{\prime}-1$ be packed into a rectangle $R_{N}$ of length $\frac{1}{2}$ as in Figure 3. By [26], the squares from $10^{9}+1$ to $B$ and from $C+1$ to $D$ can be arranged as in Figure 3. By Lemma $1, \frac{1}{C^{\prime}}+\cdots+\frac{1}{C_{0}-1}<$ $\frac{1}{A}+\cdots+\frac{1}{B}$

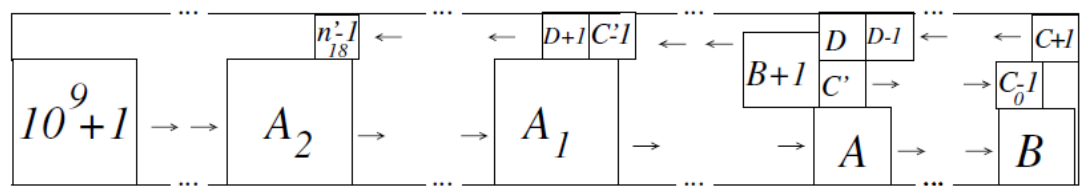

Figure 3

The squares in $R_{N}$

It is shown that the highest horizontal edge belongs to the square $C^{\prime}-1$ thus, the width of the rectangle $R_{-} N$ is $\frac{1}{A_{1}}+\frac{1}{C^{\prime}-1}=1.36381330718 \ldots \cdot 10^{-9}$.

First, it is shown that the highest horizontal edge belongs to the square $C^{\prime}-1$ among the squares $B+1, \ldots, C^{\prime}-1$. The square $C^{\prime}-y$ sits on the square $A_{1}+x$ if the relative interior of the bottom side of $C^{\prime}-y$ and the relative interior of the upper side of $A_{1}+x$ have a nonempty intersection. Since: 


$$
\frac{\frac{1}{A_{1}}}{\frac{1}{C^{\prime}-1}}=2.5 \ldots
$$

at most three squares sit on the square $A_{1}+x$ if $x$ is a (small) positive integer. It is assumed, that the square $C^{\prime}-y$ sits on the square $A_{1}+x$. Thus

$$
\frac{1}{A_{1}}+\frac{1}{C^{\prime}-1}>\frac{1}{A_{1}+x}+\frac{1}{C^{\prime}-1-3 x} \geq \frac{1}{A_{1}+x} \frac{1}{C^{\prime}-y}
$$

if $0<x \leq x_{1}$, where $x_{1}=350300705$ (the value of $x_{1}$ comes from the Octave). By Lemma 1, the square $y_{1}=1958123269$ sits on the square $A_{1}+x_{1}$, but $y_{1}+$ 1 does not sit on $A_{1}+x_{1}$. Since:

$$
\frac{\frac{1}{A_{1}+x}}{\frac{1}{y_{1}}}=1.4 \ldots
$$

at most two squares sit on the square $A_{1}+x_{1}+x$ if $x$ is a (small) positive integer. It is assumed, that the square $y_{1}-y$ sits on $A_{1}+x_{1}+x$. Thus:

$$
\begin{aligned}
& \frac{1}{A_{1}}+\frac{1}{C^{\prime}-1}>\frac{1}{A_{1}+x_{1}+x}+\frac{1}{y_{1}-2 x} \\
& \geq \frac{1}{A_{1}+x_{1}+x}+\frac{1}{y_{1}-y}
\end{aligned}
$$

if $0<x \leq x_{2}$, where $x_{2}=334746954$ (the value of $x_{2}$ comes from the Octave). Since $A_{1}+x_{1}+x_{2}>A$, the highest horizontal edge belongs to the square $C^{\prime}-1$ among the squares $B+1, \ldots, C^{\prime}-1$.

Similarly:

$$
\frac{1}{A_{2}}+\frac{1}{n_{18}^{\prime}-1}>\frac{1}{A_{2}+x}+\frac{1}{n_{18}^{\prime}-1-3 x}
$$

if $0<x \leq A_{2}-A_{1}-1$

and 


$$
\begin{aligned}
& \frac{1}{C^{\prime}}+\frac{1}{D^{\prime}-1}>\frac{1}{C^{\prime}+x}+\frac{1}{D-2 x} \\
& \text { if } 0<x \leq C_{0}-C^{\prime}-2
\end{aligned}
$$

The candidates of the width of the rectangle $R_{N}$ are

$$
\begin{aligned}
& \frac{1}{A_{2}}+\frac{1}{n_{18}^{\prime}-1}=1.3620053 \ldots \cdot 10^{-9} \\
& \frac{1}{A_{1}}+\frac{1}{C^{\prime}-1}=1.36381330719 \ldots \cdot 10^{-9} \\
& \frac{1}{A}+\frac{1}{C^{\prime}}+\frac{1}{D-1}=1.36381330718 \ldots \cdot 10^{-9}
\end{aligned}
$$

Thus the width of the rectangle $R_{N}$ is $\frac{1}{A_{1}}+\frac{1}{C^{\prime}-1}=1.36381330719 \ldots \cdot 10^{-9}$ It is necessary to find a place to pack the squares $n_{100001}$ to $n_{100251}-1$.

Let:

$$
b_{1}=\frac{1}{n_{18}\left(1+l_{0}-\frac{1}{n_{18}}\right)^{99983}}=5.40035404 \ldots \cdot 10^{-11}
$$

Now:

$$
\frac{1}{n_{i}} \leq \frac{1}{n_{100001}}<\frac{1}{n_{18}\left(1+l_{0}-\frac{1}{n_{18}}\right)^{99983}}=b_{1}
$$

for $i=100001, \ldots, 100250$ and let:

$$
b_{2}=\frac{1}{n_{100001}}+\frac{1}{n_{100001}+1}+\cdots+\frac{1}{n_{100251}-1}<250 \cdot l_{0}
$$

The square $y_{n}=1656583751$ sits on the square $x_{n}=1615268375$. (Observe, $y_{n}-1$ does not sit on $x_{n}$.) Thus:

$$
\sum_{\mathrm{i}=\mathrm{B}+1}^{\mathrm{y}_{\mathrm{n}}-1} \frac{1}{i}<250 \cdot \mathrm{l}_{0}<\sum_{\mathrm{i}=\mathrm{B}+1}^{\mathrm{y}_{\mathrm{n}}} \frac{1}{i}
$$


and

$$
\sum_{\mathrm{i}=\mathrm{x}_{\mathrm{n}}+1}^{\mathrm{A}-1} \frac{1}{i}<250 \cdot \mathrm{l}_{0}<\sum_{\mathrm{i}=\mathrm{x}_{\mathrm{n}}}^{\mathrm{A}-1} \frac{1}{i}
$$

Let:

$$
h=\frac{1}{A_{1}}+\frac{1}{C^{\prime}-1}-\frac{1}{x_{n}}-\frac{1}{y_{n}}=1.41071997485 \ldots \cdot 10^{-10}
$$

Since the highest horizontal edge belongs to the square $y_{n}$ among the squares $B+$ $1, \ldots, y_{n}$, there is a rectangle $R_{f}$ of dimensions $250 \cdot l_{0} \times h$ which has no common interior point with the squares up to $n_{18}^{\prime}-1$. Since $b_{1}<h$ and $b_{2}<250 \cdot l_{0}$, the squares from $n_{100001}$ to $n_{100251}-1$ fit in $R_{f}$.

Thus the reciprocal squares are contained in a rectangle of dimensions

$$
\frac{1}{2} \times\left(2\left(\frac{\pi^{2}}{6}-1\right)+1.36381330719 \ldots \cdot 10^{-9}\right)
$$

which shows that $\epsilon \leq 6.81906653597 \ldots \cdot 10^{-10}$

\section{Conclusions}

From the above proof, it should be recognised, that performing difficult calculations with the help of computers and/or suitable programs, can be an easy task. Without a computer, the calculations on a piece of paper, indeed, take a very long time.

Calculations with Octave and the two short retval functions, is an easy task. The numbers $A, B, C, D$ and $E$ come from [26]. The numbers $A_{1}, A_{2}, C^{\prime}, C_{0}, C_{1}, \ldots, C_{18}$ and the width of the rectangle $R_{-} N$ are calculated with the help of Octave. By Lemma 1, the control of round-off errors is achieved.

The packing question in this paper, for $\epsilon$, was asked back in 1968, and the question is still open. In the papers [26] [27] [29] [30] improved estimates for the value of $\epsilon$ can be found, but these estimates were not final, as you can see by the evidence of this paper. This short work should inspire authors to closely examine long standing mathematical questions, with the help of a computer.

\section{Acknowledgement}

This work was supported by EFOP-3.6.1-16-2016-00003 funds. Establishment of long-term $\mathrm{R}$ and $\mathrm{D}$ and I processes at the University of Dunaújváros. 


\section{References}

[1] Baranyi P., Gilányi A.: Mathability: emulating and enhancing human mathematical capabilities, Proceedings of the $4^{\text {th }}$ IEEE International Conference on Cognitive Infocommunications (CogInfoCom), Budapest, Hungary, 2013, pp. 555-558

[2] Baranyi P., Csapo A., Varlaki P.: An overview of research trends in coginfocom. Proceedings of the $18^{\text {th }}$ International Conference on Intelligent Engineering Systems (INES), Tihany, Hungary, 2014, pp. 181-186

[3] Török M., Tóth J., Szöllösi A.: Foundations and perspectives of mathability in relation to the coginfocom domain, Proceedings of the $4^{\text {th }}$ IEEE International Conference on Cognitive Infocommunications (CogInfoCom), Budapest, Hungary, 2013, pp. 869-872

[4] Baranyi P., Csapo A., Sallai G.: Cognitive Infocommunications (CogInfoCom), Springer, 2015

[5] Biró P., Csernoch M.: Deep and surface metacognitive processes in nontraditional programming tasks, Proceedings of the $5^{\text {th }}$ IEEE Conference on Cognitive Infocommunications (CogInfoCom), Vietri sul Mare, Italy, 2014, pp. $49-54$

[6] Biró P., Csernoch M.: The mathability of computer problem solving approaches, Proceedings of the $6^{\text {th }}$ IEEE Conference on Cognitive Infocommunications (CogInfoCom), Győr, Hungary, 2015, pp. 111-114

[7] Chmielewska K., Ciskowska W., Glazik D, Marcinek D., Wojciechowska K., Gilányi A.: Learnability - are we ready for distance learning?, Proceedings of the $11^{\text {th }}$ IEEE International Conference on Cognitive Infocommunications (CogInfoCom), Online, 2020, pp. 465-470

[8] Chmielwska K., Gilányi A., Łukasiewicz A.: Mathability and mathematical cognition, Proceedings of the $7^{\text {th }}$ IEEE Conference on Cognitive Infocommunications (CogInfoCom), Wroclaw, Poland, 2016, pp. 245-250

[9] Chmielwska K., Gilányi A., Mathability and computer aided mathematical education, Proceedings of the $6^{\text {th }}$ IEEE Conference on Cognitive Infocommunications (CogInfoCom), Győr, Hungary, 2015, pp. 473-477

[10] Chmielewska K., Gilanyi A.: Educational context of mathability, Acta Polytechnica Hungarica, Vol. 15, No. 5, 2018, pp. 223-237

[11] Kővári A., Rajcsányi-Molnár M.: Mathability and Creative Problem Solving in the MaTech Math Competition, Acta Polytechnica Hungarica, 17(2), 2020, pp.147-161

[12] Szi B., Csapo A.: An outline of some human factors contributing to mathability research, Proceedings of the $5^{\text {th }}$ IEEE Conference on Cognitive Infocommunications (CogInfoCom), Vietri sul Mare, Italy, 2014, pp. 583586 
[13] Bognár L., Fauszt T.: Different learning predictors and their effects for Moodle Machine Learning models, $202011^{\text {th }}$ IEEE International Conference on Cognitive Infocommunications (CogInfoCom), Mariehamn, Finland, 2020, pp. 405-410

[14] Bognár L., Fauszt T., Nagy G. Zs.: Analysis of Conditions for Reliable Predictions by Moodle Machine Learning Models, to International Journal of Emerging Technologies in Learning, accepted

[15] Bognár L., Fauszt T.: The Effectiveness of Different Sets of Learning Predictors in Moodle Machine Learning Models, Acta Polytechnica Hungarica, accepted

[16] Katona J. Kovari A, Heldal I., Costescu C., Rosan A., Demeter R., Thill S., Stefanut T.: Using Eye- Tracking to Examine Query Syntax and Method Syntax Comprehension in LINQ, Proceedings of the $12^{\text {th }}$ IEEE International Conference on Cognitive Infocommunications (CogInfoCom), Naples, Italy, 2020, pp. 437-444

[17] Katona J., Ujbanyi T., Sziladi G., Kovari A.: Examine the effect of different web-based media on human brain waves, Proceedings of the $8^{\text {th }}$ IEEE International Conference on Cognitive Infocommunications (CogInfoCom), Debrecen, Hungary, 2017, pp. 407-412

[18] Katona J., Ujbanyi T., Sziladi G., Kovari A.: Electroencephalogram-Based Brain-Computer Interface for Internet of Robotic Things, In Cognitive Infocommunications, Theory and Applications, 2019, pp. 253-275

[19] Kővári A., Katona, J., Costescu, C.: Evaluation of Eye-Movement Metrics in a Software Debugging Task using GP3 Eye Tracker, Acta Polytechnica Hungarica, 17(2), 2020, pp. 57-76

[20] Kővári A., Katona J., Costescu C.: Quantitative Analysis of Relationship Between Visual Attention and Eye-Hand Coordination, Acta Polytechnica Hungarica, 17(2), 2020, pp. 77-95

[21] Borus G. Gy., Gilányi A.: Computer assisted solution of systems of two variable linear functional equations, Aequationes mathematicae, 94(4), 2020, pp. 723-736

[22] Borus G. Gy., Gilányi A.: On a computer program for solving systems of functional equations, Proceedings of the $4^{\text {th }}$ IEEE International Conference on Cognitive Infocommunications (CogInfoCom), Budapest, Hungary, 2013, p. 939

[23] Borus G. Gy., Gilányi A.: Solving systems of linear functional equations with computer, Proceedings of the $4^{\text {th }}$ IEEE International Conference on Cognitive Infocommunications (CogInfoCom), Budapest, Hungary, 2013, pp. 559-562 
[24] Gilányi A.: Solving linear functional equations with computer, Math. Pannon., Vol. 9, No. 1, 1998, pp. 57-70

[25] Gilányi A., Merentes N., Quintero R.: Presentation of an animation of the mconvex hull of sets, Proceedings of the $7^{\text {th }}$ IEEE Conference on Cognitive Infocommunications (CogInfoCom), Wrocław, Poland, 2016, pp. 307-308

[26] Paulhus M.: An Algorithm for Packing Squares. J. Combin. Theory Ser. A., 82, 1997, pp. $147-157$

[27] Meir A., Moser, L.: On packing of squares and cubes. J. Combin. Theory Ser. A., 5, 1968, pp. 126-134

[28] Brass P., Moser W. O. J., Pach J.: Research Problems in Discrete Geometry, Springer-Verlag, New York, 2005, pp. 121-122

[29] Jennings D.: On packing unequal rectangles in the unit square. J. Combin. Theory Ser. A., 68, 1994, pp. 465-469

[30] Ball K.: On packing unequal squares. J. Combin. Theory Ser. A., 75(2), 1996, pp. 353-357

[31] Joós A.: On packing of rectangles in a rectangle. Discrete Math., 341(9), 2018, pp. 2544-2552

[32] Grzegorek P., Januszewski, J.: A note on three Moser's problems and two Paulhus' lemmas. J. Comb. Theory, Ser. A., 162, 2019, pp. 222-230 